\title{
The inflow and adaptation of Russian ICDHS Constructivism on the Korean typographic culture in the 1920s-1930s
}

\author{
Sun-A Jeong / Min-Soo Kim / Seoul National University / Seoul / Korea
}

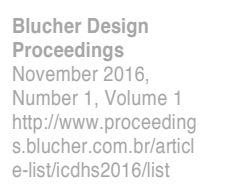

\begin{abstract}
The aim of this study is researching the interaction between Russian constructivist graphic image and the East Asian typography, particularly Korean typography which has different features, compared to Western letters. For this purpose, graphic design that appeared in media such as newspapers, magazines and books during the 1920-30s in Korea is investigated. In conclusion, Russian constructivist images in Korea were composed with traditional calligraphy and created distinctive visual culture because of the political and economic colonial condition at that time, while constructivist images in Russia and Europe were used mainly with sanserif typography that considered to have international characteristic.
\end{abstract}

\section{Keywords}

Constructivism, Korean typography, Korean design history, sanserif typography, modernity

\section{Introduction}

Russian Constructivism was active around the time of the 1917 Bolshevist Revolution. Constructivism represented the "new age" brought about by the Bolshevic revolution. This style's character was revolutionary, radical, and connected to other avant-garde European artistic movements that sought experimentation and innovation, including Dadaism, Futurism, and De Stijl. Meanwhile, the world was undergoing the reorganization of political structures after WW1. "Modernization" was also pursued in Korea, a colony of the Japanese Empire, as it had the will needed by weaker countries to survive independently among world powers. Consequently, different ideologies clashed over the nation's direction. In this environment, the "Western" and "Modern" style of Constructivism entered to the colonized Korea and other parts of East Asia through magazines, posters, and book covers where the socialist ideas were depicted.

This study examines how the socialist ideology and style responded and adapted to Korea typography, which is distinctly different from the Western typography. Through this process, I expect to reveal a specific cultural amalgamation process of how a certain type of image can be adapted to the typographic characteristics and societal conditions of a different culture.

\section{Russian Constructivism and typography}

The stylistic characteristics of Constructivist graphic work by designers such as El Lissitzky and Rodchenko can be summarized as dynamicity through asymmetry. Dynamicity was revealed in plane graphics, and was the trait most valued by Tatlin, the de-facto leader of Productivism, when constructing the Monument to the Third International in 1919 as the head of the artistic college of the IZO(section of visual arts) of the Narkompros(People's Commissariat for Education). Led by IZO, Constructivism excluded decoration and showed asymmetrical dynamicity, and came to be accepted as the visual style embodying the ideology of Russia's revolutionary government, carrying out the political propaganda and demagogy of government agencies. Constructivism faithfully signified socialism.

The sanserif typestyle first appeared in English type specimens in the 19th century. It represented a font that was optimized for the printing machine, and ended the tradition of the black letter type, representing the influence of writing tools. Robin Kinross, in his Modern typography: an essay in critical history, describes the acceptance of the sanserif typestyle in the early 20th century, saying, "The preference for sanserif is directly related to the typestyle befitting the modern age of machines." Therefore, in Constructivist typography, the meaning behind 
utilizing the sanserif typestyle goes beyond delivering messages: it can be used as an image representing the new production methods and its efficacies of the that age - the age of machines - that internalized the revolutionary spirit emphasizing everyday life and production, while declaring a severance from the past.

Constructivist characteristics of asymmetrical composition, geometric elements, strong color

contrasts, and color layers made for a mutually responsive relationship with the sanserif typeface, because the sanserif typeface excluded the decorative effects of serif, and in the space of a layer, the strokes functioned as geometric shapes. Moreover, the neatly organized outlines of the sanserif typeface, when organized with other geometric elements in the Constructivist layer, are similar in form and therefore mutually interact within one space rather than separating into texts or images, making it easier to display new effects.

Figure 1 is an advertising poster of the Leningrad State Press designed by Rodchenko. The text differently arranged, it did not fit in square box as general typography used to do. Letters were not simply for reading nor fixed in form within a square box; they were "images" just like other formative elements such as lines and layers, enabling their playful manipulation. Moreover, the fact that the reading direction of letters is free in many Constructivist images supports the notion that texts were utilized as images.

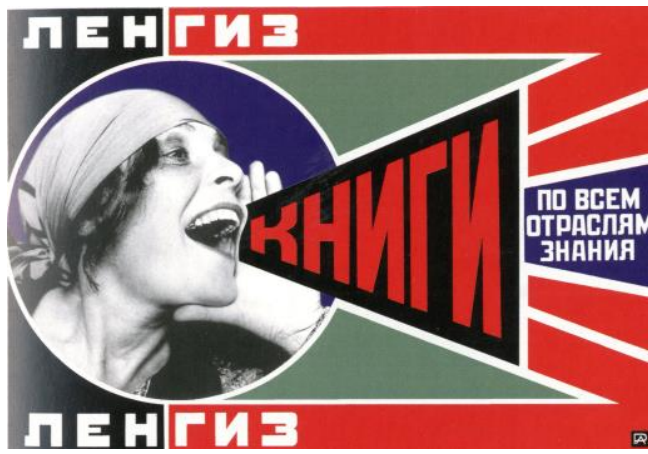

Fig. 1: Rodchenko, Advertisement for the Leningrad State Press, 1924
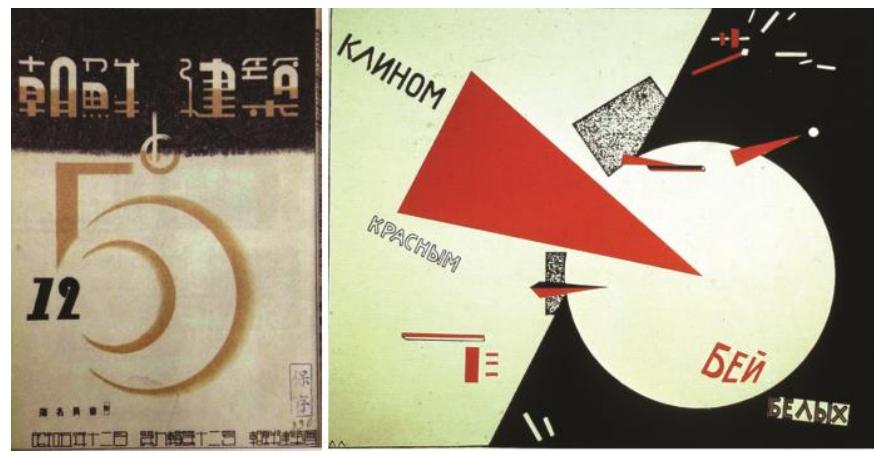

Fig. 2: The cover of Joseongwa Geonchuk designed by Lee Sang, 1930, and 'Beat the Whites with the Red Wedge!' (1919) by El Lisstzky

\section{The introduction of Constructivism in Korea in the 1920s and 1930s}

It is difficult to ascertain the exact routes through which Constructivism was introduced in Korea. Some possibilities include the 1921 visit to Japan by Constructivist artist Bubnova, leading to the reception of Russian Constructivism and its influence on an international student in Japan during this period. And Koreans in Russia, having immigrated to the Maritime Province in the 19th century, visited Korea in the 1920s for the purpose of cultural exchange. Based on such evidence, it seems natural that Constructivism was introduced to the Korean Peninsula. Yong-chul Kim (2010), who studied Japan's modern graphic design and acceptance of the Russian avant-garde phenomenon in Japan and Korea, noted the influence of Japanese Constructivism on Korean magazine covers and title designs of the 1920s and 30s such as Joseon Munye (1925) and Sacho (1927), deeming them an "effect of the acceptance of Russian avant-garde art in Japan." Moreover, researcher Min-soo Kim, through his work Yi Sang Pyeongjeon (2012), compared the morphology of the covers of Joseongwa Geonchuk designed by Lee Sang (generally known as a literary figure) and 'Beat the Whites with the Red Wedge!' (1919) designed by Russian Constructivist designer El Lisstzky, and discussed the influence exchanged between these. (Figure 2)

Among the covers of the magazines published in the 1920s, it can be seen that a new visual style was introduced in Korea and to the public, from their resemblance with the <MAVO > - a journal of a Japanese constructivist organization. In the 1930s, avant-garde activities in Japan had been oppressed, however in Korea, prints in constructivist style became more common compared to 1920 s(Figure 3). It is because the colonial rule changed to "Cultural Governance", press agencies rapidly inceased. In other words, increasing of daily information led increasing contacts with the styles of information-constructivist style.

In Korea and Japan, Russian Constructivism images carried out the functions of revolutionizing and inspiring the public by urging the revolution of the proletariat class and criticism of capitalism. Like the Bolshevik Revolution, it carried the avant-garde spirit of moving forward into a new age by destroying the old. Image was aligned with production, such as labor, industry, and machinery; with classes such as the bourgeoisie and the proletariat; and with innovation in terms of colonies such as independence and autonomous survival. Magazines expressing such spirit and serving such purposes revealed themselves to the public through the visual styles of 
Constructivism, characterized by asymmetric composition, photomontages of humans, and the placement of geometric shapes.

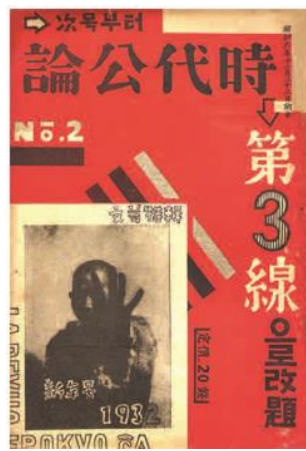

Fig. 3: Magazines in Korea in the 1930s

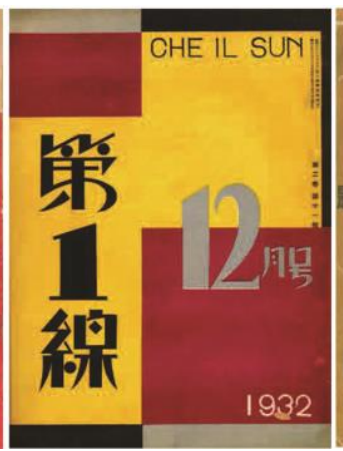

932

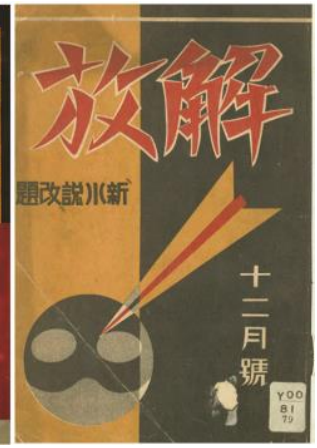

踩

\section{The characteristics of Constructivist images adapted in Korea}

In the beginning of the 20th century, the sanserif typeface prompted discussions on both sanserif typeface's reading effectiveness and its being "national/international" in its inevitability in containing regional cultures. Serif displays the individuality of text. This is because text reflects the influence of the writer's physique (overall posture, pressure from the hand, among other factors), and the influence of the writing tool utilized in a particular culture. Jan Tschichold, who considered the "new typography" to be under the influence of Russian avant-garde art, especially that of EI Lissitzky, explained "elemental typography" in Typografische mitteilungen, a German typography journal, asserting that the "purpose of the new typography lies in communication," and defining typography as a method of communicating what is to be shown (the effectiveness of reading).

Moreover, "the typeface with strong ethnicity is not a typeface that is elementally designed, (which the new typography aims for) and that limits the potential for international communication." - it means the sanserif typeface excludes the potential for the influence of a certain stereotype from ethnic character, facilitating and achieving international and effective communication. As seen above, the Constructionist visual style was recognized in the West through the need of the times for visual unity and international communication; however, in the nonalphabetic culture of Korea, the problem of "image and typography" was recognized differently than in the West. While the Constructivist style book covers and posters for advertising and incitement purposes in Russia chose sanserif typeface that excluded the influence of the writing tool, in Korea, were preferred the typeface that appeared to be heavily influenced by brushstrokes and emotions. Even if the typography was geometrically refined on paper for unity with images, the swooping-up marks of Asian characters, which are regarded anatomically as the serif of the alphabet, display their presence undeniably as reading elements, rather than being excluded.

Two magazine covers in Figure 4 clearly display the differences in the typographies of western Constructivists and cultures that utilize Chinese characters. Both covers utilize traditional Constructivist visual styles, including strong colour contrasts, colourful layers, photomontages, overprinting effects, and dynamic perspective compositions. Compared to such visually organized images, the typography of the titles strongly displays the characteristics of brush writing cultures. Traits such as brush-up marks resulting from brush pressure and dots resembling water droplets are characteristics of Asian calligraphy, and unobservable in the western alphabet. The brush-up marks and horizontal strokes in the title of Daejung seem rather linearly refined; however, they are clearly different from the sanserif alphabet, which is extremely geometric in form. In Russia, the outline of the text was organized and typography carried out through diagonal ordering, or through controlling the widths and lengths of strokes; however, in Korea, as seen on the cover of Daejung, each of the characters is uplifted at the top-right corner, displaying dynamicity internally in the text. This displays the influence of vertical writing in Asian calligraphy. In summary, while the Constructivist elements and typography were dealt with as one image on one layer in Russia, the Korean example displays clear distinctions as image and text. Moreover, while the western alphabet (Cyrillic script in this paper) is unified stylistically with Constructivist elements, in the Asian brush writing cultures of China and Korea, letters are displayed ethnicity; even if they are refined in tandem with geometric elements, they are decoratively organized regardless of the natural structure of the text, and tend to be less standardized compared to the unified sensation of the sanserif alphabet. Figure 5 shows the difference between the mainland Russian Constructivist image and Korean 

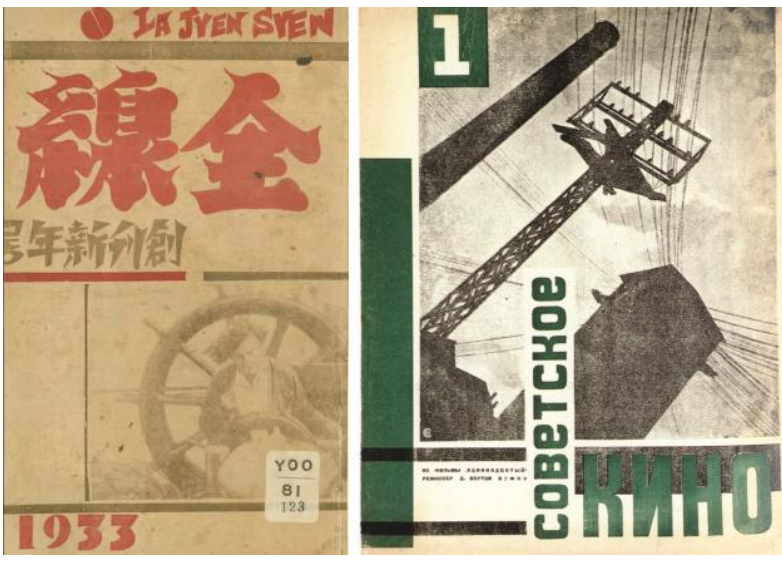

Figure 5: 1933, Korean magazine Jeonseon; 1927, Russian magazine Soviet Younghwa image.

As such, the stylistic divide of elemental images and typography apparent in the Korean Constructivist designs is due to 1) the difference between text systems from an expressive standpoint, and 2) the age-specific background of modernization and nationalism. Chinese and Korean characters are ideograms, and to express one letter, many strokes are needed in one rectangular frame. This text system is entirely different from the grapheme alphabet, which is organized in a straight line in one direction. In the case of the alphabet, the organizing of graphemes for the communication is done only from left to right; however, in Chinese characters, the notion of top and bottom exists within one

character. From the perspective of reading the text, character recognition may be performed instantaneously, without observing the sides and corners, with sufficient familiarity with the text; however, from the perspective of making and aligning the text forms, the number of strokes, and their gaps and overlaps act as complicated restrictions for readability. Compared to the alphabet, which has a relatively simple form of graphemes to distinguish sound, Chinese characters are ideograms, and elements such as dots and strokes, distinguishing sound and meaning, are more detailed.

Typographically, brush-up marks and dots, akin to the serif of the alphabet, cannot be overlooked in the geometric refining of the strokes, as they are directly related to the meaning and sound of the text. From the perspective of familiarity with the western alphabet, while the form of brush-ups and brushstrokes are functional in nature, they could be seen as decorative and expressive; therefore, by embracing such small reading elements, it is difficult to attain the "elemental typography (as opposed to typeface with strong ethnicity)" asserted by Jan Tschichold, which would be the geometric product of eliminating such elements.

When various avant-garde movements including Constructivism were active, unlike the West's focus on this "utopian" ideological internationalization, East Asia faced the dual challenge of counter to western imperialism and dealing with the issue of self-identity. In East Asian nations under the rule of colonial powers, socialist art movements strived for modern ideals through resisting the colonial powers and endevouring for national independence. The "meaning" of nationalism, striving for the internal unity of the people and the nation, was much more important than the effectiveness of typography or "technical" unity in the layer on paper. The subjects of persuasion were the "Korean compatriots," and the style that allowed for the visualization of the oneness of the Koren race enabled more effective communication, as opposed to the sanserif typeface, which purposely excluded ethnicity.

\section{Conclusion}

This paper examined how Russian Constructivism, carrying the spirit of the age, interacted with the typography of Chinese character cultures such as that of Korea. The Constructivist graphic style is characterized by the imbalanced dynamicity, along with the asymmetrical composition, the geometric elements, the colourful layers, the photomontages, and the overprinting. Based on the above criteria, this paper examined the Korean graphic design that seemed to have been significantly influenced by the Constructivism as a socialist visual style. The typography utilized along with Constructivist images in the East Asian nations such as Korea and Japan showed a strong ethnic color, and was perceived as very different emotion compared to the sanserif-focused typography of mainland Russia, which excluded such elements.

In propaganda design, the Korean Constructivist style and typography displayed the separation of text and image while the interaction of typography and Constructivist style on one layer in Russia. Such separation comes from the strong reflection of the brush as writing utensil, a fundamental difference in typography between the two nations, and from its visual difference with the geometric style of Constructivism. There are two main reasons for the strong ethnic color in Korean typography while using the Constructivist style. First, it is difficult for the reading elements of Chinese, which are both phonetic and ideographic in nature and composed of brush-up marks and dots, to be geometrically refined, as they are functional; as such, it is difficult to achieve the "elemental typography" (the new typography) characterized by the sanserif typeface. Secondly, in the western-focused modernization process, 
the West chose the sanserif typeface in order to exclude ethnicity and improve international communication; however, Korea, which used Chinese characters, had to counter to the West, and considered the uplifting of self-identity through ethnicity as well as independence. It therefore needed to confirm homogeneity through displaying ethnic color, which led to internal unity.

The Constructivist style disseminated across mainland Russia was led by the state, and was depicted in images by artists belonging to a state-sponsored organization. At a point when other ideologies were forbidden and oppressed by the state, the continued indoctrination of the ideology was demanded, and Russian Constructivism in the 1920 s offered a response to this demand. However, communism existed as one of the ideologies of modernization in Korea and Japan; in the process of persuading the public to select it as the "ideal" ideology, Constructivist images were utilized to offer a visualization of the ideology. To enable effective communication of ideological messages, Constructivism in the two nations had to express not only the socialist ideology based on the theory of class, but also patriotism. In other words, the result of the clash between the radical new image presented by the Constructivist visual style and the background sketched in this paper was the merging of the geometrically refined Constructivist formats of Russia and the ethnic typography based on calligraphy.

\section{References}

Min-soo Kim. (2012) A Critical Biography of Yi Sang, Seoul: Greenbee.

Min-hwan Kim. (1996) Korean Press Agencies, Seoul: Social Criticism.

Bok-jin Kim et al. (1995) Collection of works by Bok-jin Kim. Seoul: Chungnyunsa.

Mee Ryang Jung. (2012) The cultural movements of Korean students in Japan: The individual and the nation - the boundaries of their convergence and divide, Paju: Jisik Sanup.

Duk Gyo Choi. (2004) 100 years of Korean magazines, Seoul: Hyeonamsa.

舊韓末, 在日韓國留學生手 民族運動 研究, Gwangju: 全南大學校, 1991.

Burke, C. (2013) Active Literature: Jan Tchichold and the new typography, Seoul: Workroom.

Lodder, C., Translated by Jin-guk Jung. (1990) Russian Constructivism, Seoul: Yulhwadang.

Kinross, R., Translated by Sung-min Choi. (2009) Modern typographyan essay in critical history. Yongin: Spectre Press.

Himeji Shiritsu, B. and H. Insatsu, (2007) 大正レトロ・昭和モダン広告ポスターの世界: 印刷技術と広告表現 の精華, 東京: 国書刊行会.

Matsuoka, S. et al. (1999)日本のタイポグラフィックデザイン 1925-95: 文字は黙っていない, 東京: トラン スアート.

White, S. (1988) The Bolshevik poster, New Haven: Yale University Press.

Solomon, R. G. M. et al. (1992) The great utopia: The Russian and Soviet avant-garde, 1915-1932, New York: Guggenheim Museum. Distributed by Rizzoli International Publications.

Yong-Chul Kim. (2010) "The graphic design of the modern Japan and the adoption of the Russian avantgarde art." Asian Culture (26): 83-104.

Sung-soo Kim. (2004) "Nationalism in the socialist literature in the Japanese colonial era," Journal of Korean Literary History (24): 68-94.

Mee Ryang Jung. (2008) "The Japanese support for Korean students in Japan and its nature," Korean Journal of History of Education, 30: (1)-61.

\section{Biographical note}

Sun-A Jeong, DD. Candidate, Design History and Culture, Seoul National University. Published papers are about the history of Korean school emblem design (2014), the visual spectacles of 'Science day' in colonial Korea(2014).

Min-Soo Kim, Professor and Director of Design History and Cultural Studies, graduate course of Seoul National University(www.snu-dhc.com); Received Ph.D from New York University in USA.; Former chief editor of The Journal of Design Culture and Criticism (JDCC, 1999 2002), the first journal of cultural history, theory and criticism on design in Korea. 